\title{
O PROBLEMA DA EXTENSÃO DO CONHECIMENTO NA HIPÓTESE REGULACIONISTA DA ILUMINAÇÃO EM AGOSTINHO DE HIPONA*
}

\author{
Daniel Rodrigues da Costa** \\ https://orcid.org/0000-0002-3389-6435 \\ dan.costaecosta@gmail.com
}

RESUMO O objetivo deste artigo é analisar o problema da extensão e do conteúdo da iluminação uma vez que se adote a interpretação regulacionista para a teoria do conhecimento de Agostinho. O regulacionismo, tese defendida por Etienne Gilson, afirma que a iluminação divina do intelecto humano diz respeito ao caráter necessário dos conhecimentos alcançados pela inteligência, e não sobre o conteúdo do conhecimento; assim, a iluminação não teria por função auxiliar na formação de conceitos, mas teria a função de julgar a adequação desses conceitos à verdade. Entretanto, interpretações desse tipo trazem um problema quanto à autonomia cognitiva humana, já que o intelecto seria constrangido externamente em relação ao seu conhecimento. Trataremos, ainda, da crítica sobre a exagerada ênfase na epistemologia que a hipótese regulacionista reverbera. Por fim, e de acordo com o regulacionismo, buscaremos dar uma resposta coerente ao problema da extensão do conhecimento oriundo da iluminação, respeitando tanto a singularidade do raciocínio humano quanto a primazia do conhecimento divino.

Palavras-chave Iluminação, regra, noção, conhecimento. 
ABSTRACT The aim of this article is to analyze the issue of the extension and the content of the illumination once the regulationist interpretation for the theory of knowledge of Augustine is adopted. Regulationism, a thesis advocated by Etienne Gilson, states that the divine illumination of the human intellect concerns the necessary character of the knowledge attained by intelligence, not the content of knowledge; Thus, illumination would not have it as an auxiliary function in the formation of concepts, but would have the function of judging the adequacy of these concepts to the truth. However, interpretations of this kind bring with it a problem regarding human cognitive autonomy, given the intellect would be constrained externally in relation to its knowledge. We will also deal with the criticism about the exaggerated emphasis on epistemology in which the regulationist hypothesis reverberates. Finally, and according to regulationism, we will seek to give a coherent answer to the issue of the extension of knowledge from illumination, respecting both the uniqueness of human reasoning and the primacy of divine knowledge.

Keywords illumination, rule, notion, knowledge.

\section{A doutrina da iluminação em destaque - a hipótese regulacionista}

Os problemas decorrentes da consideração epistemológica da doutrina da iluminação de Agostinho são extensos e alimentam o debate entre os especialistas. A versão corrente do atual debate tem como foco o problema da extensão da iluminação divina no processo cognitivo humano, uma vez que se considere a iluminação como uma hipótese sobre o nosso conhecimento. Ainda que interpretações centradas nos problemas ontológicos e morais tenham importância no debate - e talvez a resposta aos problemas epistemológicos não possa ser conquistada sem elas -, quando se consideram os textos fundamentais da iluminação agostiniana, essas interpretações possuem um lugar seguro. Nesse sentido, debater sobre a semelhança da alma humana com os inteligíveis puros, ou sobre a necessidade de aperfeiçoamento moral para uma aproximação da verdade não chega a ser o problema central da iluminação. É na teoria do conhecimento, no problema do conhecimento humano, que devemos focar e buscar, nos textos fundamentais de Agostinho, a solução para o problema da extensão da iluminação.

Por conseguinte, adotar a posição dominantemente epistemológica para a teoria da iluminação significa decidir por alguns caminhos em detrimento de outros. A primeira escolha que fazemos se dá na decisão sobre o pano de fundo 
em que iremos abordar o problema da extensão da iluminação no conhecimento humano. Das diversas interpretações que a teoria recebeu ao longo dos séculos, adotaremos aquela que mais encontra base textual em Agostinho e aquela que gera maior consenso entre os estudiosos: a hipótese regulacionista (seguimos, assim, Van der Bos, 2017, p. 47).

Na historiografia de interpretações que nos é apresentada por Fulbert Cayré (1947, pp. 227-243), ${ }^{1}$ entre as interpretações medievais, a de São Boaventura aparece rivalizando com a interpretação tomista e poderia ser compreendida como precursora das interpretações extrinsequistas, ou seja, as interpretações que defendem que a iluminação divina age sobre nossa cognição ditando normas ou regras para o processo de conhecimento. Embora Cayré nomeie a tese de Boaventura de exemplarismo (ibidem, p. 227) e ressalte uma confusão no aspecto lógico da teoria, podemos compreendê-la assim. Lydia Schumacher, recentemente, não obstante se posicione contra o viés da interpretação, também compreende que a tese boaventuriana seria a precursora da compreensão da iluminação enquanto reguladora do processo de cognição (Schumacher, 2010, p. 378). Mas, no que se refere ao conjunto de interpretações de viés extrinsequista, a forma final deste tipo de interpretação ficou a cargo da teoria regulacionista de Etienne Gilson.

Partindo das dificuldades que Agostinho identifica na teoria da anamnese de Platão, como o problema da preexistência da alma e a recordação de conteúdos empíricos, Gilson pode ler na filosofia agostiniana um contraponto a essas dificuldades ao mesmo tempo que se elabora uma teoria do conhecimento singular. Embora devedora da filosofia platônica - e plotiniana -, a teoria do conhecimento de Agostinho é suficientemente inovadora para percebermos ali mais do que a recepção de influências. O que Gilson faz é ler nos textos de Agostinho, na doutrina da iluminação, tanto uma resposta à anamnese platônica quanto uma explicação para um tipo específico de conhecimento que os homens demonstram.

Se a anamnese não é aceita por Agostinho como tese sobre a formação de nossos conhecimentos, ele teria de propor uma nova tese sobre nossa cognição mais elevada. Segundo Gilson, para o bispo de Hipona, os conhecimentos não oriundos da experiência descobertos em nossa mente $\left(m e n s^{2}\right)$ estão depositados

1 Segundo Cayré, entre as interpretações medievais temos o exemplarismo de São Boaventura e o abstracionismo de São Tomás; e entre as contemporâneas, a teoria da visão parcial direta de Deus, defendida por J. Hessen, e a teoria regulacionista, proposta por Gilson.

2 Mens compreende a função da "parte" superior da alma, e engloba o intelecto (intellectus ou intelligentia), a vontade (voluntas) e a memória (memoria). Optamos por traduzir como "mente" por preservar o sentido de função. 
na memória; ${ }^{3}$ esses conhecimentos são aqueles que não possuem qualquer relação com o sensível - motivo de abandono da tese platônica - e não são do tipo que aumenta o nosso arcabouço de conceitos. Como exemplos desse tipo de conhecimento, Gilson nos diz que:

Quando ele [Agostinho] cita casos de noções que revelam a iluminação divina, os primeiros que lhe vêm ao pensamento são: a justiça, a castidade, a fé, a verdade, a caridade, a bondade e outros do mesmo gênero, que se referem aos inteligíveis puros. Quando o intelecto aplica a iluminação divina aos conceitos sensíveis, como ao de arco ou ao de homem, não é para formar uma noção acerca deles, mas para formular sua lei ou para definir-lhes o tipo necessário, o que nenhuma experiência sensível poderia nos revelar (Gilson, 2006, p. 187).

No fenômeno da iluminação, quando esse tipo de conhecimento é alcançado pelo intelecto, Agostinho não entende que o processo nos traga a aquisição de um conceito qualquer: segundo ele, a iluminação revela-nos uma noção (notio). O conceito, no sentido lato, teria ainda algum tipo de relação com o objeto sensível (ver Cayré, 1947, p. 227). Já a noção desempenha no texto agostiniano o papel de regra, ou seja, seu uso é feito no sentido estrito de designar um conhecimento apodíctico. ${ }^{4}$ Ela é o princípio no qual se fundamentam nossos juízos verdadeiros, a partir de sua relação com a própria verdade. Neste sentido, rechaçado todo empirismo que pudesse haver naquilo que é oriundo da iluminação, esse tipo de conhecimento diz respeito aos inteligíveis puros e teria por função definir a adequação daquilo que conhecemos à verdade.

Um dos grandes pontos que perturbam a teoria da iluminação pode ser resolvido já, preliminarmente: a iluminação não possui qualquer participação no processo que leva ao conhecimento dito sensível. Ainda que se possa alegar que, por se referir ao conhecimento verdadeiro, ela estaria presente em todo e qualquer processo de cognição que se arrogue ser verdadeiro (Schumacher, 2010, p. 375), a iluminação é uma condição especial do intelecto e atua sobre os conhecimentos mais elevados. Agostinho não se refere à iluminação quando se trata de saber se o gosto de tal alimento é doce ou amargo; a atenção da alma para com os sensíveis que provocam o corpo que ela anima é suficiente para explicar esse tipo de conteúdo mental. A iluminação é requerida quando se trata de explicar conhecimentos presentes na memória que não foram adquiridos no

3 Conf. X, VIII. O erro dos platônicos teria sido concluir, a partir disso, que a alma se lembrava de conhecimentos, e por isso teria vivido anteriormente, quando, na verdade, a função da memória é essencialmente uma função do presente. Cf. livros X das Conf. e XIV do De Trin.

4 Por apodíctico entendemos o caráter de necessidade que o conhecimento verdadeiro implica, segundo Gilson, 2006, p. 182. 
processo exemplificado acima, como as noções de felicidade, justiça, beleza etc.

Quando se refere ao termo "noção" no contexto epistemológico, Agostinho comumente o utiliza no sentido de "noção impressa". Isso significa que teríamos impressas em nossa mente certas noções a partir das quais julgamos os demais conhecimentos. Essas noções não foram impressas em um tempo cronologicamente anterior à nossa atual existência, conforme proporia a tese platônica, mas descobertas a partir da interiorização, elas seriam a prova da semelhança da alma com os inteligíveis puros. Todo conhecimento que o homem possui está em sua memória, mas nem tudo o que está na memória do homem foi adquirido pela ação do intelecto: as noções impressas são depositadas de acordo mesmo com a criação da alma, ou seja, é um tipo de conhecimento que é constitutivo dela. ${ }^{5}$ Quando o intelecto se encontra iluminado, ele é capaz de realizar o processo de interiorização para encontrar na memória essas noções impressas, conquistando a certeza de sua inteligibilidade.

Agostinho dá-nos um exemplo de como essas noções impressas operam em nossa mente:

Desse modo, assim como antes de sermos felizes possuímos impressa em nossa mente a noção da felicidade, visto ser por ela, com efeito, que sabemos com firmeza e sem nenhuma hesitação afirmamos que queremos ser felizes. Assim também, antes de sermos sábios, nós temos impressa em nossa mente a noção da sabedoria. Em virtude da qual cada um de nós, ao ser questionado se quer ser sábio, responde sem sombra de hesitação que o quer. ${ }^{6}$

Além de identificarmos que a noção possui um sentido apriorístico diríamos, mais precisamente, inato -, ela está aqui desempenhando o papel de regra, ou seja, é o julgamento a partir do qual ela própria se explicita. Assim, a noção de felicidade nada mais é do que o estado da alma que alcança a segurança na intelecção e posse de algo imutável, a noção de sabedoria nada mais é do que a correta compreensão da criação e a preferência do eterno ao temporal; e é necessário que tenhamos essas noções em nossa memória para que possamos desejar aquilo que é adquirido na posse delas. Todas as demais noções que Agostinho afirma termos impressas em nossa mente são do mesmo tipo: a noção de justiça é dar a cada um o que lhe convém, caridade é amar

5 É o que Dixsaut chama de "pertencimento ontológico" (2017, p. 99); Rist, 1994, p. 31.

6 De lib. arb. II, IX, 26: "Sicut ergo antequam beati simus, mentibus tamen nostris impressa est notio beatitatis; per hanc enim scimus, fidenterque, et sine ulla dubitatione dicimus beatos nos esse velle: ita etiam priusquam sapientessimus, sapientiae notionem in mente habemus impressam, per quam unusquisque nostrum si interrogetur velitne esse sapiens, sine ulla caligine dubitationis se velle respondet." 
o próximo pelo amor em Deus, a fé é persistir na ordem divina, e assim por diante. Todas, portanto, possuiriam um caráter apodíctico, ou seja, a partir do momento em que são descobertas, impõem-se como um princípio normativo, destacado seu caráter de necessidade. A noção, por conseguinte, desempenharia a exata função que o termo "regra" (regula) desempenha no texto de Agostinho.

Tal como na passagem supracitada de Gilson (2006, p. 187), a iluminação atua em nossa mente a fim de revelar conteúdos que incidem em nossa capacidade de julgar os objetos sensíveis e as ações morais, por assim dizer. Quando observo um arco que não é tal como deveria ser, há uma ação do intelecto que, diante da observação do dado empírico, projeta-lhe sua versão perfeita e seus critérios normativos. Da mesma forma, quando, ao ver uma atitude ímpia ser chamada de justa, eu julgue equivocada a situação, ocorre uma atividade do intelecto a partir da descoberta da noção impressa de justiça. Essa forma de manifestação da verdade, em que nossa mente é iluminada pela luz divina e se torna capaz de, primeiro, descobrir em si as noções impressas e, segundo, julgar as coisas a partir do princípio normativo da verdade, essa forma de manifestação é o essencial da doutrina da iluminação. A luz divina, não obstante, embora seja presente à nossa mens, não pertence a nós por direito, mas é uma ação divina que nos tem como receptáculo natural (Conf. XII, XXV, 35).

Essa interpretação, que enfatiza a iluminação como verificadora e garantidora de nossos juízos, é o essencial da tese regulacionista. Poder-se-ia dizer que Gilson é imprudente ao identificar regras e noções, identificação a partir da qual se fundamenta a ideia de que as noções são a lei divina que guia o homem, mas esse movimento não é feito de ímpeto (Gilson, 2006, p. 188); o movimento é atingido nos textos de Agostinho:

De fato, pois, entre todos esses bens - aqueles que mencionei, ou outros que são vistos ou imaginados - não poderíamos dizer que um é melhor que o outro, quando julgamos de acordo com a verdade, se a noção do bem em si não estivesse impressa em nós. ${ }^{7}$

Da mesma forma, no que diz respeito às imagens de coisas materiais desenhadas através dos sentidos do corpo e infundidas na memória, por meio das quais formamos, também coisas que não vimos, representações imaginárias (sejam elas, essas imagens, diferentes ou, por acaso, correspondendo à realidade), ainda é de acordo com regras completamente diferentes, regras imutáveis que transcendem o nosso espírito, que aprovamos ou desaprovamos de nós mesmos, quando o aprovamos ou desaprovamos de acordo com o julgamento correto. ${ }^{8}$

7 De Trinitate VIII, III, 4: "Neque enim in his omnibus bonis, vel quae commemoravi, vel quae alia cernuntur sive cogitantur, diceremus aliud alio melius cum vere iudicamus, nisi esset nobis impressa notio ipsius boni."

8 De Trinitate IX, VI, 10: "Unde etiam phantasias rerum corporalium per corporis sensum haustas, et quodam modo infusas memoriae, ex quibus etiam ea quae non visa sunt, ficto phantasmate cogitantur, sive aliter quam 
Afirmar que a iluminação auxilia em nosso conhecimento judicativo por meio das noções impressas, que são regras a partir das quais conhecemos a verdade de determinados conteúdos cognitivos, é, provavelmente, uma tese segura. ${ }^{9}$ É preciso verificar se os problemas atualmente apontados à teoria da iluminação possuem uma resposta razoável na hipótese regulacionista. Trataremos de dois deles: o problema da passividade do intelecto e da consequente autonomia cognitiva - que já foi inicialmente tratado acima e o problema da possível negligência de aspectos ontológicos - que é um problema metodológico, mas que merece atenção. Alguns desses problemas, devemos considerar, originam-se mesmo da adoção da interpretação gilsoniana, como o problema da autonomia cognitiva do homem quando se considera a iluminação como uma ação de Deus sobre o intelecto humano; entretanto, segundo pensamos, a resposta que o regulacionismo propicia a esses problemas é mais vantajosa do que a posição contrária, de assumir a iluminação como uma capacidade interna e natural do homem.

\section{O problema da passividade do intelecto na hipótese regulacionista}

Por ser uma interpretação que tem como base a função epistemológica da iluminação, o regulacionismo é criticado, especialmente, por dois motivos: a hipótese seria demasiadamente "epistemologista", desconsiderando relações mais complexas que Agostinho havia enxergado na iluminação, e a hipótese imprimiria ao intelecto uma passividade que não condiz com a operação que dá origem ao conhecimento humano. Sobre essa última crítica, é necessário notar que ela se oferece a todas as interpretações chamadas "extrinsequistas" da iluminação, já que estas supõem que o intelecto receba "de fora" (Schumacher, 2010 , p. 399) aquilo que é sua função fundar. De acordo com tais críticas, se o conhecimento é condicionado pela luz divina quando esta interage com o intelecto humano, ele não mais seria o produto adquirido por meio do raciocínio discursivo no processo ordinário da mente, mas a iluminação determinaria a certeza de nossos pensamentos externamente ao nosso intelecto. Até que ponto o pensamento poderia ser dito nosso uma vez que toda a validade do processo cognitivo se encontra fora da mente humana? Como afirma Pasnau, esse tipo de interpretação exige que expliquemos, por conseguinte, como a mente divina

sunt, sive fortuito sicuti sunt, aliis omnino regulis supra mentem nostram incommutabiliter manentibus, vel approbare apud nosmetipsos, vel improbare convincimur, cum recte aliquid approbamus aut improbamus."

9 Sobre a aproximação de sentidos dos termos "noção" e "regra", ver: Cayré, 1947, pp. 189-190; Marrou, 1995, pp. 70-71; Rist, 1994, pp. 50, 76; entre outros. 
pode influenciar a nossa mente sem que isso signifique que nosso intelecto se torne obsoleto, ou, no melhor dos casos, passivo e secundário (ver Pasnau, 2015 [s.p.]).

Uma das críticas feitas a esse tipo de problema, que ataca as posições extrinsequistas em geral, é rememorada por Lydia Schumacher. Com o mérito de consolidar o vocabulário atual, Schumacher (2010, pp. 375-379) afirma que as interpretações correntes da doutrina da iluminação se dividem em interpretar a iluminação como um "condicionamento intelectual extrínseco", ou seja, o conhecimento adquirido e validado mediante uma ação externa de Deus sobre o intelecto, e em interpretar a iluminação como uma "fonte de capacidade cognitiva intrínseca", ou seja, o conhecimento adquirido e validado por meio de uma restauração de nossa natureza enquanto imagem de Deus. Segundo ela, autores como Bruce Bubacz e Etienne Gilson adotam diferentes variáveis do chamado extrinsequismo, enquanto ela própria, ao lado de autores como Maurice de Wulf e Charles Boyer, adota a posição intrinsequista (ibidem, p. 377). ${ }^{10}$ Ainda segundo Schumacher, a posição que interpreta a iluminação como um condicionamento extrínseco de nosso conhecimento, embora possa requerer apoio textual de Agostinho, desconsidera o contexto adequado da teoria e, ainda, enreda-se em tantos problemas que torna impossível sua validade. Um desses problemas é a passividade do intelecto, pois, se a iluminação sustenta todo o processo de cognição e a certeza do pensamento de uma maneira externa ao próprio intelecto, não se pode dizer que o conhecimento seja humano em alguma medida (ibidem, p. 398).

Já no século passado, o professor Fernand Van Steenberghen afirmava que a hipótese gilsoniana não explicava a natureza da luz que ilumina o intelecto e colocava em risco a atividade do intelecto humano. Para Van Steenberghen, não se pode concluir, a partir da tese de que a iluminação diz respeito ao conhecimento verdadeiro, que ela não possui participação na formação dos conceitos. Se isso for correto, a tese gilsoniana peca ao negligenciar a atividade do intelecto iluminado, enquanto sua função própria, na busca pelo conhecimento; tanto Gilson quanto outros intérpretes de Agostinho restringiram a atividade do intelecto para deixar espaço para a operação da iluminação, o que tornaria o intelecto humano passivo e sem participação na aquisição do

10 A interpretação da iluminação enquanto um condicionamento intelectual intrínseco defende que a função da iluminação é recuperar a capacidade cognitiva que o homem possui enquanto imagem divina; assim, mediante analogias trinitárias, Schumacher demonstra que a luz ilumina a mente trina para que a mente ilumine o mundo (2010, pp. 395-398). 
conhecimento mais elevado (Van Steenberghen, 1933, pp. 267-268). Assim, embora Gilson afirme que a iluminação diga respeito "menos" à formação de conceitos do que ao conhecimento verdadeiro, para Van Steenberghen, a tese regulacionista retira do intelecto a sua função característica de atividade:

O Sr. Gilson, como vimos, não envolve a iluminação divina para explicar a origem dos conceitos pelos quais nós conhecemos as coisas corporais: os inteligíveis já estão nas imagens, onde a inteligência os alcança diretamente. Acreditamos, ao contrário, que o inteligível, para Agostinho, é a ideia, irredutível à imagem e ao fruto da atividade suprema da alma; e é no exercício dessa atividade que a alma é iluminada pela luz divina. Sua função, então, é tornar a inteligência capaz de perceber em si ideias ou essências inteligíveis, com seus caracteres de generalidade, necessidade e imutabilidade; e perceber, além disso, as relações necessárias dessas ideias entre si ou os primeiros princípios da dialética e das ciências normativas (ibidem, pp. 268-269). ${ }^{11}$

Desse modo, tanto Van Steenberghen, na década de 1930, quanto Schumacher, em tempos recentes, criticam Gilson por postular uma iluminação apenas formal, quando, na realidade, a iluminação também é a explicação para o enriquecimento de nosso conhecimento material, ou, nas palavras desta última, responsável pela "renovação da imagem de Deus [e por trazer] essa imagem embaçada para um foco mais claro" (Schumacher, 2010, pp. 397-398). Por conseguinte, a tese regulacionista, ao propor apenas o aspecto formal da iluminação, deixaria obscura a epistemologia agostiniana, pois não seria capaz de resolver nem a questão da natureza da luz que ilumina o intelecto, nem a questão da "natureza profunda da verdade" (ibidem, p. 239).

Especificamente sobre o regulacionismo proposto por Etienne Gilson, que de primeira mão afirma que sua hipótese é nada mais que provável, a análise e crítica das interpretações acima que trazem o inevitável problema da passividade do intelecto esbarram em um limite teórico. Quando Agostinho se refere à iluminação no contexto epistemológico, ele fala sobre a verdade e sobre como ela é compreendida pela mente humana, como em Conf. XII, $\mathrm{XXV}, 35$ : "Se nós dois vemos que o que você diz é verdade, e nós dois vemos que o que eu digo é verdade, então onde nós vemos isso? Não eu em você,

11 "M. Gilson, nous l'avons vu, ne fait pas intervenir l'illumination divine pour expliquer l'origine des concepts au moyen desquels nous, connaissons les choses corporelles : les intelligibles se trouvent déjà dans les images, où l'intelligence les atteint directement. Nous croyons, au contraire, que l'intelligible, pour S. Augustin, c'est l'idée, irréductible à l'image et fruit de l'activité suprême de l'âme ; et c'est dans l'exercice de cette activité que l'âme est éclairée par la lumière divine. Celle-ci a donc pour rôle de rendre l'intelligence capable de percevoir en elle-même les idées ou les essences intelligibles, avec leurs caractères de généralité, de nécessité, d'immutabilité; de percevoir, en outre, les relations nécessaires de ces idées entre elles ou les premiers principes de la dialectique et des sciences normatives". 
nem você em mim, mas nós dois nessa verdade inalterável que está acima de nossas mentes." 12

A verdade é aquilo que transcende nossa mente e que garante, por essa mesma transcendência, que o conhecimento que alcançamos seja correto, seguro e imutável. Como afirma Pasnau, é a iluminação que nos propicia passar da mera crença para o conhecimento seguro (Pasnau, 2015, [s.p.]). ${ }^{13}$ Mas a nossa mente não obtém essa verdade diretamente da mente divina, como queriam os ontologistas (ver Nash, 2003) ${ }^{14}$ a iluminação propicia que o intelecto descubra a verdade enquanto uma noção impressa em nossa memória. E, quando Agostinho fala de noções impressas, ele fala de um tipo específico de conhecimento: uma noção é, por definição, uma regra impressa em nossa memória. Ao ser questionado sobre a extensão do conhecimento oriundo da iluminação, Agostinho deixaria claros dois pontos, que são rememorados por Gilson (cf. De div. Quaest. 83, 51; Conf. IX, X; Gilson, 2006, pp. 167 e 191): primeiro, que há uma diferença definitiva entre o conhecimento natural, ordinário, e o conhecimento sobrenatural, extraordinário e oriundo da experiência mística; e, segundo, que a iluminação não possui relação direta com o conhecimento oriundo da relação da alma com os sentidos, ou seja, com o conhecimento sensível. Dito isto, o caso da iluminação diz respeito aos juízos adquiridos ou descobertos no processo natural do conhecimento, e se resumem a uma ação da luz divina sobre o intelecto.

Existe uma diferença entre a iluminação natural e a sobrenatural: a segunda diz respeito ao fenômeno místico, em que a verdade se coloca diante da mente; a iluminação natural, da qual tratamos, refere-se ao modo de condução do intelecto para a descoberta das verdades: a iluminação dá-se na descoberta do caráter necessário do conhecimento adquirido. Afirmar, entretanto, que a tese regulacionista restringiria a ação do intelecto na busca e contemplação da verdade só faz sentido se confundirmos os âmbitos natural e sobrenatural do conhecimento, o que não ocorre nem em Agostinho nem em Gilson. Por conseguinte, a operação natural do intelecto é preservada independentemente da iluminação, ${ }^{15}$ pois a alma se volta ao mundo para retirar dele o conteúdo básico de sua intelecção. É no encontro da certeza desses conhecimentos que a iluminação se manifesta.

12 "si ambo videmus verum esse quod dicis et ambo videmus verum esse quod dico, ubi, quaeso, id videmus? Nec ego utique in te nec tu in me, sed ambo in ipsa quae supra mentes nostras est incommutabili veritate."

13 "Illumination is what allows us go to from mere true belief to knowledge, [...] illumination provides justification."

14 Nash argumenta em favor de uma visão ontologista sutilmente modificada, mas que persiste com a ideia de que a mente veria as coisas em Deus (2003, p. 102).

15 No sentido epistemológico, pois a alma é dependente da iluminação no sentido ontológico e moral. 
Para compreender isto, é necessário entender a diferença entre o conceito e a verdade aplicada ao conceito. Vamos tomar dois exemplos de noções complexas: ${ }^{16}$ onipresença e eternidade. A onipresença é a capacidade de ser presente em todos os momentos e em todos os lugares, ao mesmo tempo e sem nenhuma modificação da própria substância. A eternidade é um estado, próprio de Deus, em que não há mudança, anterioridade ou sucessão, e cuja extensão não pode ser medida. Ambas as noções requerem que o intelecto conjugue o inteligível obtido a partir da empiria com as concepções de normatividade que essas noções possuem. Assim, embora suponham o conhecimento do mundo sensível e que não possam ser concebidos sem o inteligível retirado do sensível - ação operativa do intelecto -, esses conhecimentos se caracterizam como regras que definem os parâmetros de outros conhecimentos. Não se pode dizer, assim, que uma infinita duração temporal seja eternidade, assim como que a divisão de uma substância infinitas vezes garantiria sua onipresença. Essas noções são normativas e definem o escopo de um conhecimento; elas exigem, contudo, que o intelecto opere de modo a retirar do mundo a inteligibilidade que o constitui. A iluminação incide na certeza da noção, mas ela não rompe a autonomia da cognição humana, ela não torna o intelecto passivo: ela apenas define onde se encontra a verdade de nossos conhecimentos. ${ }^{17}$ Assim, por exemplo, quando investiga se determinada disciplina é adequada à busca pela sabedoria, o intelecto opera de acordo com sua função natural; quando, entretanto, percebe a noção de sabedoria impressa em sua memória, não há mais espaço para a operação judicativa, pois a noção é clara e evidente em sua natureza normativa. ${ }^{18}$

Poder-se-ia dizer, contudo, que a iluminação é necessária em todo processo cognitivo, numa espécie de iluminação contínua, que nos acompanha ao longo de nossas vidas, e não apenas no encontro das certezas de nossos juízos. Quem não percebe, entretanto, que esse tipo de iluminação é aquele a que Agostinho

16 O termo é derivado da dificuldade de se compreender a extensão da iluminação e refere-se aos conhecimentos tipicamente oriundos dela. O termo não aparece na exposição de Gilson, mas é um desdobramento lógico ante a necessidade de compreender a extensão das noções impressas. Uma noção, enquanto conhecimento apodíctico, possui uma extensão: elas não são regras vazias, mas, ao se explicitarem, evidenciam a verdade do conhecimento adquirido. Existem, entretanto, noções que aparentemente exigem mais do que a evidência da verdade que exprimem, elas necessitam de conhecimento de base empírica para poderem se expressar.

17 Todo esse processo, conhecido como interiorização, é parte da operação do intelecto. Ao perceber, enfim, as certezas que buscava em si própria, a mens (pois o intelecto não opera isoladamente, mas conjuntamente da vontade e da memória) não mais opera no sentido judicativo que possui o intelecto. A ratio (função operativa) e a intelligentia (o "produto" da operação) são funções ativas do intelecto que visam identificar, reunir, analisar e julgar os dados oriundos do mundo; quando em contato com as noções impressas na mens, contudo, o intelecto não mais julga no sentido de definir-lhes a adequação à verdade.

18 "A necessidade do verdadeiro para a razão não é mais que o sinal da sua transcendência sobre ela. A verdade, na razão, está acima da razão" (Gilson, 1995, p. 147). 
se refere ao falar sobre o homem enquanto imagem de Deus, ou seja, uma iluminação do tipo moral e ontológica?

Mas o que eu amo quando te amo? Não uma beleza corpórea, nem uma graça temporal: nem o esplendor da luz, tão querido por estes meus olhos, nem as doces melodias entoadas em todos os tons, nem a fragrância das flores, unguentos e aromas, nem maná ou o mel, não membros aceitando os abraços da carne. Nada disso eu amo, quando eu amo meu Deus. Eu ainda amo uma espécie de luz e voz e cheiro e comida e abraço quando amo meu Deus: luz, voz, cheiro, comida, o abraço de meu homem interior, onde uma luz brilha para minha alma, não encoberta no espaço, onde ressoa uma voz que não é subjugada pelo tempo, onde se encontra um perfume não disperso pelo vento, onde um sabor não é captado pela voracidade, onde se abraça aquilo que não é quebrado pela saciedade. Eu amo isso quando eu amo meu Deus (Conf. X, VI, 8). ${ }^{19}$

Citar passagens como Solil. I, 8, 15, ${ }^{20}$ em que Agostinho define a necessidade de Deus para a compreensão de todas as coisas, não atinge o efeito pretendido, qual seja, de garantir que a iluminação seja contínua. A inteligibilidade que Deus propicia é a que garante que tenhamos um conhecimento seguro, e não que tenhamos qualquer tipo de crença. Como afirma Van Der Bos, a iluminação não precisa excluir a atividade do intelecto humano porque ela é uma "capacidade extra" às nossas habilidades cognitivas (Van der Bos, 2017, pp. 52-53). A ideia de parceria é a mais adequada para pensarmos a relação da iluminação com o intelecto humano, no curso natural do conhecimento. Assim, o aspecto formal do regulacionismo compreende a normatividade das noções impressas, sem implicar na passividade do intelecto humano e garantindo certa autonomia cognitiva. Quando se trata da verdade, entretanto, sua transcendência ao intelecto humano é explícita ao concluirmos que o homem não produz suas certezas, ele as encontra (Gilson, 2006, pp. 164-167):

Ativo, o pensamento agostiniano anima primeiro e em relação ao corpo, e, sob a notificação deste, produz as sensações; em seguida, em relação às imagens particulares assim engendradas, ele une, dissocia, compara e lê o inteligível. Mas logo aparece no pensamento algo que nem os objetos, que ele pensa, nem ele mesmo, que os pensa, poderiam explicar: o julgamento verdadeiro, com o caráter de necessidade que ele

19 "Quid autem amo, cum te amo? Non speciem corporis nec decus temporis, non candorem lucis ecce istis amicum oculis, non dulces melodias cantilenarum omninodarum, non florum et unguentorum et aromatum suaveolentiam, non manna et mella, non membra acceptabilia carnis amplexibus; non haec amo, cum amo Deum meum. Et tamen amo quamdam lucem et quamdam vocem et quemdam odorem et quemdam cibum et quemdam amplexum, cum amo Deum meum, lucem, vocem, odorem, cibum, amplexum interioris hominis mei, ubi fulget animae meae, quod non capit locus, et ubi sonat, quod non rapit tempus, et ubi olet, quod non spargit flatus, et ubi sapit, quod non minuit edacitas, et ubi haeret, quod non divellit satietas. Hoc est quod amo, cum Deum meum amo".

20 "Ergo quomodo in hoc sole tria quaedam licet animadvertere; quod est, quod fulget, quod illuminat: ita in illo secretissimo Deo quem vis intellegere, tria quaedam sunt; quod est, quod intellegitur, et quod caetera facit intellegi". Passagem citada por Schumacher (2010, p. 375). 
implica. A verdade do julgamento é o elemento tal que, sem poder produzi-lo, o pensamento deve receber (ibidem, p. 182). ${ }^{21}$

\subsection{Ainda sobre a normatividade da noção complexa}

Para esclarecer melhor a razão de uma noção dita complexa ser normativa, oriunda da iluminação, e não um conceito oriundo da abstração, vamos exemplificar com o caso de uma noção que Agostinho define em seus textos e que serve de base para compreendermos como uma noção é descoberta: a felicidade. Certamente uma das noções primárias e à qual Agostinho frequentemente faz alusão (e. g. Conf. X, XX, 29; De Trin. XIV, III), a felicidade pode ser usada aqui para exemplificar o modo de manifestação do conhecimento típico oriundo da iluminação.

A partir do momento em que conclui que a felicidade é uma noção impressa, ${ }^{22}$ surge um problema sobre a interação das faculdades da mens: poder-se-ia imaginar, pois, que a felicidade é apenas a lembrança da alegria acrescida pela imaginação de um gozo contínuo. Se assim for, a felicidade não é um conhecimento oriundo da iluminação, com o caráter de necessidade que ele implica, mas seria apenas o típico caso de uma interação das faculdades da memória e da imaginação operando com os dados oriundos dos sentidos. Para solucionar essa questão, Gilson demonstra que Agostinho entende que a lembrança da felicidade é condição de possibilidade para toda experiência relativa à felicidade - considerando o caráter verdadeiro que a felicidade carrega -, pois alegrar-se verdadeiramente com algo é necessariamente reconhecer a verdade deste algo, e amá-la (Conf. X, XXII). O amor à verdade, e, por conseguinte, o amor à felicidade, ${ }^{23}$ só é possível se a verdade e a felicidade não forem ignoradas (De Trin. VIII, IV). Logo, a felicidade é conhecida não a partir de uma experiência de alegria, pois a experiência de verdadeira alegria só é proporcionada mediante o reconhecimento da verdade de tal experiência. É, pois, a experiência de alegria que é reconhecida como verdadeira alegria por meio da noção de felicidade que está presente na memória.

21 A passividade do intelecto poderia ser aludida no caso da experiência mística, em que o intelecto é elevado à contemplação da verdade divina sem margem judicativa. No caso do conhecimento natural, existe o reconhecimento da normatividade e da universalidade da noção.

22 Todos os homens querem ser felizes. Essa frase é essencial da filosofia agostiniana e indica a presença da noção de felicidade na memória de todos os homens, de modo que todos podem desejar algo de certa forma conhecido e se colocar na busca deste algo. A felicidade é uma noção, ou seja, é inata, normativa e universal; inata pois é impressa na alma desde sua criação; é normativa pois regula os atos que são capazes de alcançá-la; e é universal pois todos os homens, segundo Agostinho, desejam a felicidade. Essas três características estão presentes em todas as noções.

23 Considerando a identidade de ambas: Conf. X, XXIII. 
Essa é a diferença entre uma mera experiência de prazer e uma experiência na qual podemos identificar uma verdadeira alegria, porque na verdadeira alegria há uma identificação entre a memória da felicidade e a experiência que é vivida; já na experiência de prazer não existe essa identificação, embora estejamos sentindo prazer. ${ }^{24} \mathrm{~A}$ experiência de felicidade pode, inclusive, advir de uma experiência sensível que não envolva prazer, como nos casos dos mártires. Desse modo, não é possível que a partir da experiência de prazer e de alegria criemos em nossa mente a noção de felicidade, porque para identificar que o prazer e a alegria são verdadeiros é necessário que já tenhamos a noção de felicidade. É a noção impressa que garante a experiência, e não o contrário (cf. Gilson, 2006, p. 156).

Essa inversão de termos, com a experiência sendo ordenada pela noção impressa, é o modo de incidência da iluminação. Os dados oriundos da experiência não podem ser a base da iluminação, mas, ao contrário, a iluminação opera na garantia da verdade desses dados, por sua função de normatividade. Tal como a normatividade da noção de felicidade, a noção de onipresença, então, obtém os dados empíricos necessários à sua formulação por meio da ação ordinária do intelecto, e obtém a normatividade característica de sua verdade pela ação divina sobre o intelecto. Da mesma forma a noção de eternidade. Todos esses conhecimentos complexos são a conjunção da operação do intelecto com a incidência da iluminação; assim, não há nem a passividade do intelecto nem a iluminação incide na formação de conceitos, aumentando nosso arcabouço de conhecimentos. O que a iluminação faz é incidir no caráter necessário de nossos conhecimentos, e tão somente se manifesta quando esse caráter de necessidade é exigido, segundo Gilson. ${ }^{25}$

\section{O problema da negligência da Ontologia}

Resta pouco a falar quanto ao problema da suposta negligência ontológica que o regulacionismo proporia. Como vimos acima, quando o regulacionismo

24 Poder-se-á objetar que a experiência de prazer é uma experiência sensível, e que a experiência de alegria verdadeira, como a estamos chamando, não é desse tipo, e, portanto, a comparação é indevida. Entretanto, vale destacar que a experiência de alegria verdadeira pode ser oriunda de uma experiência sensível ou não, e o que estamos evidenciando é que ela só pode ser reconhecida como alegria verdadeira (com o caráter moral que ela carrega) se a lembrança de felicidade estiver na memória. Já a experiência de prazer e a sua consequente lembrança, quando não é identificada à verdadeira alegria, cessa apenas na experiência sensível, não há a recordação de uma memória que lhe garanta sua adequação à verdadeira felicidade.

25 “[...] pouco Ihe importa [a Agostinho], por exemplo, que uma noção seja geral ou particular; ela supõe a intervenção da iluminação divina tão logo almeje um caráter necessário, pois de nenhum número de observações, por maior que seja, pode-se deduzir que os homens são o que um único homem deve ser para satisfazer à sua própria definição" (Gilson, 2006, p. 186). 
se propõe a explicar o caso da iluminação no contexto do conhecimento natural, os casos da iluminação do tipo ontológica e moral são deixados de lado, mas apenas por uma necessidade metodológica. Não é infundada, contudo, a crítica de que Gilson proporia um intelectualismo na iluminação que seria desconhecido para Agostinho.

Jérôme Lagouanère faz este questionamento: segundo ele, existe em Gilson uma sobrecarregada ênfase na influência do plotinismo sobre Agostinho. Acontece que a interpretação de Plotino que Gilson possui é a de Émile Bréhier, que encarava todo o movimento neoplatônico como um intelectualismo encarnado pela figura de Plotino. A principal consequência disso é também a principal crítica de Lagouanère a Gilson; como grande medievalista que era, Gilson constrói uma analogia de influências que não é real: haveria um espelhamento da recepção aristotélica em Tomás de Aquino com a recepção plotiniana em Agostinho (Lagouanère, 2016, p. 13). Assim, quando o intelecto tomista opera realizando a abstração e retirando o inteligível do sensível para formar o conceito, Lagouanère acusa Gilson de projetar no intelecto agostiniano a mesma função do intelecto plotiniano. ${ }^{26}$

Esse espelhamento de recepções, que para Lagouanère não é bem fundamentado, implicaria na tese gilsoniana de que o intelecto humano descobre na iluminação as regras com as quais julga as coisas. Essa não é uma posição totalmente equivocada, pois de fato o intelecto agostiniano "toma posse de regras (règles) ou conceitos garantindo a natureza normativa dos seus juízos sintéticos a priori, tanto nos domínios teórico e prático" (Lagouanère, 2016, p. 16). ${ }^{27} \mathrm{O}$ erro de Gilson, segundo Lagouanère, está na ênfase no aspecto epistemológico da teoria, quando, na verdade, Agostinho está destacando a dependência ontológica da alma para com Deus e a iluminação como a descoberta do uerbum interior, garantidor da veracidade e da universalidade das proposições. Lagouanère questiona Gilson por se apegar ao intelectualismo plotiniano oriundo de sua analogia de recepções, de modo que a sua crítica se dá a uma tentativa de projetar problemas e soluções que não estariam presentes na filosofia agostiniana. ${ }^{28}$

26 Para Pierre Hadot (1980, pp. 246-247), na filosofia de Plotino, a alma seria, originalmente, uma das formas inteligíveis, um intelecto que se pensa no interior do Intelecto. Para tal, ver: Enéada VI, 4, 14, 16-25. Cf: Brandão, 2007.

27 O autor, aparentemente, não realiza a distinção entre regras e conceitos.

28 Segundo Lagouanère, Gilson elabora sua hipótese na esteira das discussões com Hessen e Cayré, e seu erro é abordar a questão da iluminação de acordo com uma problemática externa a Agostinho. Lagouanère, 2016, p. 16: "Sans pour autant tomber dans un historicisme outrancier, il convient de considérer les textes augustiniens dans le cadre diachronique d'une pensée en mouvement. II appert ainsi que prétendre donner une interprétation univoque de la théorie de l'illumination s'avère être une tâche herméneutique périlleuse, 
Contudo, Gilson, em momento algum, esconde que a iluminação é uma teoria sobre a nossa relação com o divino, e se a sua ênfase está na relação epistemológica, é apenas por uma questão metodológica: o pensamento, no regulacionismo, "não tem com o que se preocupar a não ser em saber onde está a fonte da verdade" (Gilson, 2006, p. 178). A verdade, pois, é um princípio formal, e não resta dúvida de que é sobre ela que a teoria da iluminação fala. Essa "natureza profunda do conhecimento", da qual fala Van Steenberghen e que parece ser a mesma mencionada por Dixsaut (Van Steenberghen, 1933, p. 239; Dixsaut, 2017, p. 99) sobre a reminiscência platônica, ela deve ser abarcada no princípio formal da verdade, enquanto noção impressa: não perceber, pois, que a noção impressa da verdade diz respeito exatamente a essa "natureza profunda" é não compreender a teoria da iluminação.

Acusar Gilson, i. e., o regulacionismo, de construir a iluminação agostiniana demasiadamente voltada à epistemologia, embora seja uma crítica válida, possui alcance limitado. Por mais que se possa acusar o regulacionismo por intelectualismo, ou mesmo por plotinismo, Gilson deixa claro, em seus textos, que não é a Plotino que Agostinho se converte nos jardins de Cassicíaco, é a Paulo.

\section{Conclusão}

O questionamento sobre a extensão da operação da iluminação no intelecto humano, por um lado, exige que nos posicionemos diante de problemas como a passividade do intelecto e o exagerado intelectualismo da teoria, mas, por outro, permite que compreendamos o alcance da tese agostiniana. Agostinho tratava do problema do conhecimento mais elevado e de como era necessária uma fundamentação transcendente desse conhecimento. A tese regulacionista de Gilson possui o mérito de respeitar essa característica essencial da teoria.

Poder-se-ia questionar que a tese gilsoniana não responde o problema da extensão da iluminação porque não responde o problema da identificação das noções que teríamos impressas em nossa memória. Essa questão, entretanto, o próprio Agostinho não respondeu, não por não haver atentado ao fato, mas pela razão mesma do modo de manifestação das noções impressas. Uma noção se manifesta apenas quando é exigido do intelecto um julgamento verdadeiro, ou seja, ela só é descoberta pela iluminação quando a própria iluminação se faz necessária. Tentar definir, portanto, quais são as noções que temos impressas 
em nossa memória só faz sentido se nos imbuirmos da tese de uma iluminação constante, em que teríamos presentes em nossa mens, sempre, todas as noções impressas. Essa tese, entretanto, se mostra absurda por exigir da iluminação uma operação que é exatamente o contrário de sua definição. Agostinho, ao explicar o que são as noções, nos dá exemplos de inteligíveis puros, como a justiça, a bondade, a caridade, a fé, etc., ou seja, aquilo que é capaz de julgar os demais conteúdos de nossa alma. Essa capacidade, contudo, somente se manifesta quando é exigida e quando a alma se encontra bem ordenada, de modo que se torna impossível realizar um "inventário" das noções impressas. Pelo fato da manifestação de algumas das noções, podemos apenas presumir sobre o aspecto lógico-formal delas.

Sabemos que o intelecto iluminado pela luz divina opera tanto com os dados que ele extrai dos sentidos quanto com a necessidade que ele alcança da iluminação. Assim, uma noção impressa manifesta-se na certeza de um conhecimento, e não na própria noção. Se, como defendemos acima e de acordo com a tese gilsoniana, as noções impressas são regras de julgamento, isso significa que todo julgamento que manifesta seu caráter necessário, universal e transcendente é parte da iluminação divina. Algumas dessas noções foram identificadas por Agostinho, mas não podemos dizer que ele tenha identificado todas e não podemos, por isso mesmo, ir além do que já exploramos na hipótese regulacionista. O problema da manifestação das noções impressas - que são a exteriorização do fenômeno da iluminação - não permite que concluamos por completo a questão sobre a extensão do que a iluminação traz ao intelecto, mas permite que compreendamos que não há passividade do intelecto humano. A hipótese regulacionista é uma hipótese sobre essa extensão - e o conteúdo é subsumido na extensão - e tem o mérito de respeitar as funções operativas do intelecto e o modo normativo necessário da iluminação.

\section{Referências}

Citamos os textos de Agostinho, em língua latina, segundo a edição coletiva S. Aurelii Augustini Opera Omnia: editio latina, organizada por Città Nuova Editrice e Nuova Biblioteca Agostiniana, e disponível em www.augustinus.it. Todas as traduções são de nossa responsabilidade.

BRANDÃO, B. “A união da alma e do Intelecto na filosofia de Plotino". Kriterion, Belo Horizonte, Vol. 48, Nr. 116, julho/dezembro de 2007.

CAYRÉ, F. “Initiation a la philosophie de saint Augustin". Paris, Études Augustiniennes, 1947. 
DIXSAUT, M. "Platão e a questão da alma". Tradução de C. S. Agostini. São Paulo: Paulus, 2017.

GILSON, E. "Introdução ao estudo de Santo Agostinho". Tradução de C. N. Ayoub. São Paulo: Discurso Editorial; Paulus, 2006. . "A filosofia na Idade Média”. Tradução de E. Brandão. São Paulo: Martins Fontes, 1995.

HADOT. "Les niveaux de conscience dans les états mystiques selon Plotin [Levels of consciousness in Plotin's mystical states]". Journal de Psychologie Normale et Pathologique, 77(2-3), 1980, pp. 243-266.

HESSEN, J. "Teoria do conhecimento". Tradução de J. V. G. Cuter. Revisão técnica de S. S. Cunha. São Paulo: Martins Fontes, 1999.

LAGOUANÈRE, J. «Le Saint Augustin d'Étienne Gilson: une lecture de l'Introduction à l'étude de Saint Augustin d'Étienne Gilson». Cahiers d'études du religieux. Recherches interdisciplinaires [En ligne], 16|2016, mis en ligne le 24 juin 2016. [Online]. Disponível em: http://journals.openedition.org/cerri/1591; DOI: 10.4000/cerri.1591 (Acessado em 09 de abril de 2019).

MARROU, H. I. "Saint Augustin et l'augustinisme”. [s.l.]: Maîtres spirituels, 1995. NASH, R. "The Light of the Mind: St. Augustine's Theory of Knowledge". Ohio: Academic Renewal Press, 2003.

PASNAU, R. "Divine Illumination". In: The Stanford Encyclopedia of Philosophy. (Spring 2015 Edition), Edward N. Zalta (ed.). [Online]. Disponível em: https://plato. stanford.edu/archives/spr2015/entries/illumination/ (Acessado em 25 de janeiro de 2019). RIST, J. M. "Augustine: ancient thought baptized". Cambridge University Press: Cambridge, 1994.

SCHUMACHER, L. "The "Theo-Logic" of Augustine's Theory of Knowledge by Divine Illumination". Augustinian Studies, 41:2, 2010.

SCOTT, D. "Platonic anamnesis revisited". The Classical Quarterly, 37 (ii), 1987, pp. 346-366.

VAN DER BOS, A. "Augustine on Knowledge Divine Illumination as an Argument against Scepticism". RMA: Religion \& Culture Rijksuniversiteit Groningen Research Master Thesis s2217473, April 2017.

VAN STEENBERGHEN, F. "La philosophie de S. Augustin d'après les travaux du Centenaire (suite et fin)". Revue néo-scolastique de philosophie, 35e année, Deuxième série, Nr. 38, 1933, pp. 230-281. 